\title{
Transcription factor 7-like 2 polymorphisms and type 2 diabetes, glucose homeostasis traits and gene expression in US participants of European and African descent
}

\author{
S. C. Elbein - W. S. Chu • S. K. Das • \\ A. Yao-Borengasser $\cdot$ S. J. Hasstedt $\cdot$ H. Wang $\cdot$ \\ N. Rasouli • P. A. Kern
}

Received: 15 December 2006 / Accepted: 25 April 2007 / Published online: 20 June 2007

(C) Springer-Verlag 2007

\begin{abstract}
Aims/hypothesis We sought to determine: (1) the role of previously described transcription factor 7-like 2 (TCF7L2) variants in type 2 diabetes in African American individuals and in participants of European ancestry; (2) the physiological impact of these variants on glucose homeostasis; and (3) whether the non-coding variants altered TCF7L2 expression in adipocytes and transformed lymphocytes. Methods Association studies were conducted by genotyping 932 Europid and African American diabetic and control participants. Family studies were conducted in 673 members of 68 Europid families ascertained for at least two diabetic siblings. Metabolic studies were conducted in 585 nondiabetic individuals who had undergone frequently sampled
\end{abstract}

Electronic supplementary material The online version of this article (doi:10.1007/s00125-007-0717-x) contains supplementary material, which is available to authorized users.

S. C. Elbein $(\bowtie) \cdot$ W. S. Chu $\cdot$ S. K. Das · A. Yao-Borengasser • H. Wang $\cdot$ N. Rasouli $\cdot$ P. A. Kern

Endocrine Section, Medicine and Research Services, Central Arkansas Veterans Healthcare System, Endocrinology 111J-1/LR, John L. McClellan Memorial Veterans Hospital,

4700 W. 7 th St,

Little Rock, AR 72205, USA

e-mail: elbeinstevenc@uams.edu

S. C. Elbein - W. S. Chu • S. K. Das • A. Yao-Borengasser •

H. Wang $\cdot$ N. Rasouli $\cdot$ P. A. Kern

Division of Endocrinology and Metabolism,

Department of Medicine, College of Medicine,

University of Arkansas for Medical Sciences,

Little Rock, AR, USA

S. J. Hasstedt

Department of Human Genetics,

University of Utah Health Sciences Center,

Salt Lake City, UT, USA intravenous glucose tolerance tests to determine insulin sensitivity and insulin secretion. Gene expression studies were conducted in 74 adipose samples and 64 muscle samples from non-diabetic individuals with known genotypes and also in 55 lymphoblastoid cell lines.

Results TCF7L2 variants were associated with type 2 diabetes in a Europid case-control population and in families, but not in African Americans. Risk alleles increased the $60 \mathrm{~min}$ post-challenge glucose value in Europid families and reduced insulin sensitivity by $45 \%$ in Europids, but did not alter insulin secretion. TCF7L2 expression was not altered by genotype and did not correlate with insulin sensitivity or BMI.

Conclusions/interpretation We confirmed TCF7L2 as a risk factor in a population of European descent, where it reduced glucose tolerance and insulin sensitivity, but not insulin secretion. We found no role in African Americans and could not explain the association by altered adipocyte or muscle gene expression.

Keywords Allelic association - Gene expression . Insulin resistance $\cdot$ Insulin secretion · Single nucleotide polymorphism $\cdot$ SNP . Type 2 diabetes $\cdot$ WNT signalling

$\begin{array}{ll}\text { Abbreviations } \\ \text { AIR }_{\mathrm{g}} & \begin{array}{l}\text { acute insulin response to glucose } \\ \text { maximally potentiated insulin response to arginine }\end{array} \\ \mathrm{AIR}_{\max } & \begin{array}{l}\text { disposition index } \\ \text { DI }\end{array} \\ \text { HOMA } & \text { homeostatic model assessment } \\ \text { OR } & \text { odds ratio } \\ \text { RR } & \text { relative risk } \\ \text { S }_{\mathrm{I}} & \text { insulin sensitivity } \\ \text { SNP } & \text { single nucleotide polymorphism } \\ \text { WNT } & \text { wingless MMTV integration site family }\end{array}$




\section{Introduction}

Despite convincing evidence from twin and family studies that type 2 diabetes has a strong genetic component, unravelling the genetic predisposition has proved frustrating. Our laboratory and many others have reported significant associations in genes identified by positional cloning efforts and/or strong candidacy, but replication of these findings has been difficult to achieve. The most widely accepted type 2 diabetes susceptibility variants, Pro12Ala in the gene encoding peroxisome proliferator-activated receptor gamma (PPARG) [1] and Glu23Lys in the beta cell potassium channel gene potassium inwardlyrectifying channel, subfamily $\mathrm{J}$, member 11 (KCNJ11) $[2,3]$ confer only a modestly increased risk of type 2 diabetes in Europids. Recently, Grant et al. [4] identified a microsatellite in intron 3 of the transcription factor 7-like 2 gene (TCF7L2) that was strongly associated with type 2 diabetes, with a combined $p$ value in Icelandic, Danish and US populations of $10^{-18}$ and a combined relative risk (RR) of 1.56. The single nucleotide polymorphisms (SNPs) rs12255372 and rs7903146 were in strong linkage disequilibrium with the microsatellite and showed similarly strong associations. Subsequent to this initial report, numerous published studies have examined this gene, with consistent replication among multiple crosssectional Europid populations [5-10] and increased risk in several prospective studies [11-13]. These studies have resulted in extraordinarily low $p$ values, odds ratios (ORs) of 1.4 to 1.9 and a risk of 1.4 per risk allele in Europid cohorts from prospective studies. Although no association was reported in African American [11] or African Caribbean [13] subsets, recently Helgason et al. [14] reported that SNP rs7903146 was associated with type 2 diabetes in families from west Africa ( $p=0.0002$, RR 1.45).

TCF7L2 binds to $\beta$-catenin downstream of wingless MMTV integration site family (WNT) to regulate proglucagon gene expression in gut endocrine L cells, but reportedly not in pancreatic alpha cells [15]. Other studies report that TCF7L2 is widely expressed, including in mature pancreatic beta cells as well as in peripheral and omental adipocytes [8]. The WNT pathway is important in adipogenesis [16]; thus, a broader physiological role for TCF7L2 in glucose homeostasis is plausible. Both Florez et al. [11] and Saxena et al. [6] reported reduced insulin secretion in response to oral glucose in carriers of the risk allele. Damcott et al. [10] examined 48 unrelated Europid individuals by frequently sampled IVGTT and found a significant association with a reduced insulin sensitivity index $\left(\mathrm{S}_{\mathrm{I}}\right)$ and the beta cell compensation for insulin resistance (disposition index [DI]), but only a marginal reduction in acute insulin response to glucose $\left(\mathrm{AIR}_{\mathrm{g}}\right)$. Munoz et al. [17] reported reduced $\mathrm{AIR}_{\mathrm{g}}$ and DI in the subset of 138 Europid and 118 African American women who were homozygous for the TT genotype at SNP rs12255372, albeit with statistical significance only in
Europids and with no association for SNP rs7903146. In contrast, Scott et al. [7] reported no association with fasting insulin, glucose tolerance, $\mathrm{S}_{\mathrm{I}}$ or DI in Finland-US Investigation of NIDDM Genetics (FUSION) families, while Cauchi et al. [18] found only non-significant trends towards reduced fasting insulin and homeostatic estimates of insulin secretion (homeostatic model assessment [HOMA]-B).

We sought to further explore the role of TCF7L2 in type 2 diabetes and prediabetic traits by testing the association of previously reported variants in 932 individuals from Europid and African American case-control populations and in 693 members of Europid families ascertained for multiple diabetic siblings. To examine the physiological impact of TCF7L2 variants, we examined 585 non-diabetic participants who had undergone frequently sampled IVGTT, including members of families ascertained in Utah and unrelated Europid and African American participants ascertained in Arkansas. Finally, we examined TCF7L2 expression in adipose tissue, muscle tissue and transformed lymphocytes by genotype. Our results suggest ethnic differences in the risk of type 2 diabetes conferred by TCF $7 L 2$ alleles. We provide support for a role of TCF7L2 variants in insulin sensitivity and impaired glucose homeostasis in Europids, but we did not find significant evidence for genotypic effects on gene expression in three different tissues.

\section{Methods}

Study participants The study populations are summarised in Table 1. We tested for an association of TCF7L2 variants with type 2 diabetes in a northern European (Europid) population primarily ascertained in Utah and in an African American population ascertained primarily in Arkansas. For both studies, diabetic participants were previously diagnosed and on pharmacological therapy or had clearly diabetic glucose tolerance tests. All diabetic patients had at least one first-degree relative with type 2 diabetes. Control participants had normal glucose tolerance tests or fasting or post-meal glucose levels below $5.6 \mathrm{mmol} / 1$. Controls were selected for no family history of type 2 diabetes in parents, siblings or grandparents. Metabolic effects of TCF7L2 variants were examined in three nondiabetic study populations. Non-diabetic members of northern European Utah families ascertained for at least two diabetic siblings underwent tolbutamide-modified, frequently sampled IVGTT, as described previously [19]. Europid participants and African American non-diabetic individuals ascertained in Arkansas were studied using either a tolbutamide-modified frequently sampled IVGTT (122 Europid, 69 African American) as described previously [20] or, because tolbutamide became unavailable during the study, an insulin-modified test $(0.04 \mathrm{U} / \mathrm{kg}$ of 
Table 1 Summary of study populations

\begin{tabular}{llllll}
\hline Population & Description & Male/female $(n)$ & BMI $\left(\mathrm{kg} / \mathrm{m}^{2}\right)$ & Age (years) & Diagnosis age (years) \\
\hline Europid case-control & Control & $72 / 115$ & $27.5(18.5,41.1)$ & $51.0(15.3)$ & - \\
& Case & $134 / 57$ & $31.1(21.9,44.2)$ & $61.7(10.7)$ & $51.5(12.1)$ \\
African American case-control & Control & $91 / 94$ & $29.5(18.8,46.3)$ & $42.8(13.3)$ & - \\
& Case & $197 / 172$ & $32.0(20.8,49.4)$ & $54.8(12.5)$ & $42.8(11.9)$ \\
Utah family study & Non-diabetic & $175 / 215$ & $27.1(13.9,40.5)$ & $43.5(16.0)$ & - \\
& Diabetic & $124 / 159$ & $29.9(21.0,42.6)$ & $57.1(14.2)$ & $48.9(12.2)$ \\
Utah Europid metabolic & Non-diabetic & $50 / 72$ & $27.5(18.3,41.3)$ & $39.3(10.5)$ & - \\
Europid metabolic & Non-diabetic & $101 / 243$ & $30.1(20.3,44.6)$ & $38.9(10.1)$ & - \\
African American metabolic & Non-diabetic & $48 / 71$ & $30.2(20.5,44.9)$ & $37.5(8.9)$ & - \\
\hline
\end{tabular}

Unless otherwise stated, values are means, shown as arithmetic means for normal variables and geometric means for skewed variables (BMI) Age is shown as mean $(\mathrm{SD})$, BMI as mean $(95 \% \mathrm{CI})$ transferred to the linear scale from the ln-transformation

insulin at $20 \mathrm{~min})$ using a similar protocol [21, 22] (217 Europids, 88 African Americans) (Table 2). Arkansas participants were ascertained for variable family history of type 2 diabetes and representing a range of weight, age at study, and glucose tolerance from normal to impaired [23, 24]. Participants underwent two visits: a standard $75 \mathrm{~g} 2 \mathrm{~h}$
OGTT with sampling at baseline, $30 \mathrm{~min}, 60 \mathrm{~min}, 90 \mathrm{~min}$ and $120 \mathrm{~min}$ for insulin and glucose and a frequently sampled IVGTT. A subset of 144 Europid and 60 African American participants underwent determination of the maximum insulin response to arginine $\left(\mathrm{AIR}_{\max }\right)$. At the conclusion of the frequently sampled IVGTT, the glucose

Table 2 Descriptive statistics of unrelated, non-diabetic participants for metabolic studies

\begin{tabular}{|c|c|c|c|}
\hline Trait & Europid & African American & $p$ value \\
\hline$n$ & 344 & 159 & \\
\hline Protocol (tolbutamide/insulin) & $125 / 219$ & $70 / 89$ & - \\
\hline Sex $($ male/female $)$ & $101 / 243$ & $54 / 105$ & - \\
\hline Age (years) & $38.9(10.1)$ & $38.4(9.2)$ & NS \\
\hline BMI $\left(\mathrm{kg} / \mathrm{m}^{2}\right)$ & $30.9(6.1)$ & $30.8(6.1)$ & NS \\
\hline \multicolumn{4}{|l|}{ WHR } \\
\hline Male & $0.951(0.071)$ & $0.927(0.058)$ & 0.04 \\
\hline Female & $0.863(0.074)$ & $0.868(0.094)$ & 0.61 \\
\hline PFAT (\%) & $36.7(9.1)$ & $34.0(10.7)$ & 0.004 \\
\hline Systolic BP (mmHg) & $115.8(15.5)$ & $111.3(15.7)$ & 0.003 \\
\hline Diastolic BP (mmHg) & $75.5(10.7)$ & $68.3(13.7)$ & $2 \times 10^{-8}$ \\
\hline Cholesterol (mmol/l) & $4.80(1.01)$ & $4.51(1.04)$ & 0.002 \\
\hline HDL-cholesterol (mmol/l) & $1.30(0.36)$ & $1.42(0.27)$ & 0.0002 \\
\hline LDL-cholesterol (mmol/l) & $2.83(8.6)$ & $2.64(4.0)$ & 0.005 \\
\hline Triacylglycerol (mmol/l) & $1.50(0.95)$ & $1.03(0.60)$ & $4.5 \times 10^{-12}$ \\
\hline $\operatorname{AUC}_{\text {glucose }}(\mathrm{mmol} / 1 \times \min )$ & $854.9(172.7)$ & $819.7(178.4)$ & 0.05 \\
\hline Fasting glucose $(\mathrm{mmol} / \mathrm{l})$ & $4.74(0.54)$ & $4.75(0.65)$ & 0.76 \\
\hline $2 \mathrm{~h}$ glucose $(\mathrm{mmol} / \mathrm{l})$ & $6.44(1.77)$ & $6.13(1.91)$ & 0.08 \\
\hline $\operatorname{AUC}_{\text {insulin }}(\mathrm{pmol} / 1 \times \min )$ & $46663(36098)$ & $54689(36656)$ & 0.03 \\
\hline Insulinogenic index $(\mathrm{pmol} / \mathrm{mmol})$ & $116.9(118.5)$ & $254.1(516.8)$ & 0.00005 \\
\hline $\mathrm{S}_{\mathrm{I}}\left(\times 10^{-4} \min ^{-1}[\mu \mathrm{U} / \mathrm{ml}]^{-1}\right)^{\mathrm{a}}$ & $4.00(4.80)$ & $3.62(3.55)$ & 0.30 \\
\hline $\mathrm{AIR}_{\mathrm{g}}(\mathrm{pmol} / 1 \times \min )$ & $2792(2108)$ & $4556(3578)$ & $1.2 \times 10^{-7}$ \\
\hline $\mathrm{S}_{\mathrm{g}}\left(\min ^{-1}\right)^{\mathrm{b}}$ & $0.0174(0.0088)$ & $0.0190(0.0082)$ & 0.13 \\
\hline $\mathrm{DI}^{\mathrm{c}}$ & $1430(1213)$ & $2168(1893)$ & 0.0002 \\
\hline
\end{tabular}

Values are shown as means (SD).

Comparisons of Europid and African American participants were ascertained similarly in Arkansas for non-diabetic glucose tolerance tests. Comparisons were by two-tailed independent samples $t$ test; skewed variables were $\ln$-transformed prior to analysis.

$B P$ : blood pressure, PFAT: per cent body fat from dual-energy X-ray absorptiometry measurement.

${ }^{\mathrm{a}}$ Units are taken from the MINMOD program. To convert values to SI units $\left(\times 10^{-4} \mathrm{~min}^{-1}[\mathrm{pmol} / 1]^{-1}\right)$ mutiply by 0.167 .

${ }^{\mathrm{b}} \mathrm{S}_{\mathrm{g}}$ is a measure of the ability of glucose to promote its own uptake.

${ }^{\mathrm{c}} \mathrm{DI}$ is calculated as $\mathrm{S}_{\mathrm{I}} \times \mathrm{AIR}_{\mathrm{g}}$ for individual values. 
was increased over $10 \mathrm{~min}$ to 23 to $25 \mathrm{mmol} / \mathrm{l}$, which was maintained for $30 \mathrm{~min}$. At $30 \mathrm{~min}$ of hyperglycaemia, a $5 \mathrm{~g}$ intravenous arginine bolus was given over $30 \mathrm{~s}$. Insulin response to arginine was measured at baseline $(25 \mathrm{mmol} /$ 1 glucose) and at 2, 3, 4, 6, 8 and $10 \mathrm{~min}$.

Family-based analyses for type 2 diabetes, lipids and glucose homeostasis traits based on $75 \mathrm{~g}$ OGTTs were conducted in 673 members of 68 Utah families for which both genotypic and phenotypic data were available, as summarised in Table 1 and reported previously $[25,26]$. A subset of non-diabetic participants from Arkansas who had had metabolic studies also underwent fat and muscle biopsies [27], including 28 participants with impaired glucose tolerance [23]. All participants provided written informed consent under approved Institutional Review Board protocols of either the University of Utah Health Sciences Center or the University of Arkansas for Medical Sciences.

Genotyping We typed rs7903146 and rs12255372 using pyrosequencing on a pyrosequencer (PSQ-96; Biotage, Uppsala, Sweden). Primer design was modified to permit use of a biotinylated universal primer. More than 110 duplicate samples were included across all studies with $100 \%$ agreement for both SNPs. The microsatellite marker DG10S478 [4] was typed by using infrared dye labelled M13 primer on a sequencer (GR4200; LI-COR Biosciences, Lincoln, NE, USA) and scored using GeneImage IR software (version 3.5.6; Scanalytics, Fairfex, VA, USA). All primer sequences are available on request. Based on strong linkage disequilibrium between the SNPs and the dichotomised microsatellite [4], only the SNPs were typed for family and metabolic studies.

Gene expression RNA was extracted from Epstein-Barr virus-transformed lymphocytes grown under standard culture conditions using either Trizol (Invitrogen, Carlsbad, CA, USA) or RNEasy (Qiagen, Valencia, CA, USA). Adipose RNA was extracted using kits (RNeasy Lipid Tissue Minikit; Qiagen). Muscle RNA was extracted using RNA kits (Ultraspec; Biotecx Laboratories, Houston, TX, USA). Reverse transcription was performed using MultiScribe Reverse Transcriptase (Applied Biosystems, Foster City, CA, USA). Because of multiple splice forms for TCF7L2 [28], we initially designed primer sets for both the $5^{\prime}$ (exons 1 and 2/3) and $3^{\prime}$ (exons 12 and 13/14) ends of the gene (Electronic supplementary material [ESM] Table 1, ESM Fig. 1). However, the $5^{\prime}$ primer set gave a single band in all tissues tested and detected all documented splice forms. Hence, we report only the results using this assay. Similar to findings in a previous report [8], we detected measurable levels of TCF7L2 message in muscle but at 10fold lower levels than in adipose. Real-time quantitative RT-PCR was conducted either on an ABI 7500 (Applied
Biosystems) or on a Rotorgene 2000 (Corbett Life Science, Sydney, NSW, Australia) using SYBR Green (Applied Biosystems). All assays were normalised to 18S RNA.

Laboratory measures Insulin was measured by the General Clinical Research Center Core Laboratory using an immuno-chemiluminometric assay (MLT Assay, Cardiff, Wales, UK). Plasma glucose was measured by using a glucose oxidase method.

Statistical analysis Allele frequencies for the case-control study were compared using the Armitage Trend and Fischer Exact tests. Hardy-Weinberg equilibrium was tested separately in diabetic and control participants using the online DeFinetti program (http://ihg.gsf.de/cgi-bin/hw/hwa1.pl). Linkage disequilibrium and haplotype associations were tested in Haploview 3.32 [29]. $\mathrm{S}_{\mathrm{I}}$ was estimated from glucose and insulin measures during the frequently sampled IVGTT using the MINMOD [30] or MONMOD Millenium programs [31]. $\mathrm{AIR}_{\mathrm{g}}$ was calculated as the mean insulin response above basal from 2 to $10 \mathrm{~min}$ following the glucose bolus for the Utah family sample or as the AUC for the same time for Arkansas Europid and African American samples. DI was calculated as $\mathrm{S}_{\mathrm{I}} \times \mathrm{AIR}_{\mathrm{g}}$. Glucose and insulin AUCs $\left(\mathrm{AUC}_{\text {glucose }}, \mathrm{AUC}_{\text {insulin }}\right)$ were calculated from the trapezoidal rule. Genotypic effects on glucose homeostasis traits $\left(\mathrm{S}_{\mathrm{I}}, \mathrm{AIR}_{\mathrm{g}}, \mathrm{DI}, \mathrm{AUC}_{\text {glucose }}, \mathrm{AUC}_{\text {insulin, }}\right.$, insulinogenic index) and obesity traits (BMI, WHR, per cent fat) were tested using mixed effect, general linear models. Skewed variables were $\ln$-transformed to normality prior to analysis. All models of glucose homeostasis traits included age and BMI as covariates and sex and genotype as fixed factors. Additionally, diagnosis and pedigree membership were included as fixed factors in analyses of family members from the Utah study. We adjusted for protocol type (tolbutamide or insulin) by including a numeric code as a fixed factor for participants studied in Arkansas [32]. Analyses of obesity traits were adjusted for age and sex. The significance of associations detected in the model was examined by comparison of marginal means using the least significant difference test. Based on the strong prior evidence and complicated correlations among analyses, we considered $p<0.05$ to be significant without presenting a correction for multiple testing. Gene expression ratios were tested after lntransformation to normality using analysis of variance or mixed effects models. All analyses were conducted in SPSS for Windows, v 12 (SPSS, Chicago, IL, USA).

Family-based analyses were conducted using measured genotype analysis. The effect of each SNP was tested using logistic regression models for type 2 diabetes and normal densities for the quantitative traits using likelihood analysis implemented in the Java version of the Pedigree Analysis Package, jPAP [33]. Significance was tested using $2 d f \chi^{2}$ 
statistics computed as twice the natural logarithm of the ratio of the likelihood upon estimating genotype-specific penetrances or means to the likelihood of a single penetrance or mean. In addition to genotype-specific penetrances or means, the effects of sex, age, BMI and polygenic inheritance were also estimated by maximum likelihood.

Power considerations Based on a Europid case and control population of 192 individuals each, a control allele frequency of 0.25 and an OR of 1.5 , we had $70 \%$ power to detect an association at $p<0.05$ or $86 \%$ power to detect an OR of 1.6. Among African Americans, we had $85 \%$ power to detect an OR of 1.5 with a control allele frequency of 0.30 in 186 control and 369 diabetic participants at $p<0.05$ or $95 \%$ power at an OR of 1.6. For the quantitative trait study in Europids, we considered a simplified model, in which carriers and rare homozygotes were grouped and traits were ln-transformed for comparison by Student's $t$ test. Notably, we used general linear regression with genotype for the actual analyses, but power analysis of that model was technically problematic. For $\mathrm{S}_{\mathrm{I}}$, we had $84 \%$ power to detect a $10 \%$ difference in $\ln \mathrm{S}_{\mathrm{I}}$ (mean $\pm \mathrm{SD}$; $3.3 \pm 0.9$ to $3.0 \pm 0.9$ ) or a difference on the linear scale of 2.7 (95\%CI $0.46-15.8)$ to $2.0(95 \%$ CI $0.34-11.7)$. For $\mathrm{AIR}_{\mathrm{g}}$, we had $92 \%$ power to detect a $5 \%$ fall in $\ln A \mathrm{IR}_{\mathrm{g}}($ mean $\pm \mathrm{SD} 6.0 \pm 0.8$ to $5.7 \pm 0.8$ ) or a difference on the linear scale from $403(95 \%$ CI $84-1,935)$ $\mathrm{pmol} / 1$ to $299(96 \%$ CI $62-1,434) \mathrm{pmol} / \mathrm{l}$.

\section{Results}

Associations of TCF7L2 with type 2 diabetes mellitus The now well-replicated association of the T allele at rs7903146 was replicated in Europids (OR 1.72, $p=0.0008$ ), with lesser associations at SNP rs12255732 and the micro- satellite DG10S478 (OR 1.46, $p=0.02$ ). In contrast, none of these markers showed any evidence for an association with type 2 diabetes in African American participants $(p>0.5)$. Results are summarised in ESM Table 2. Whereas the three markers were in strong linkage disequilibrium in Europids $\left(r^{2}>0.7\right)$, little linkage disequilibrium was observed in African Americans $\left(r^{2}<0.3\right)$ (ESM Tables 3 and 4). No significant association with BMI was seen for any SNP in Europids (data not shown), but the rs 12255372 TT genotype was nominally associated with reduced BMI in

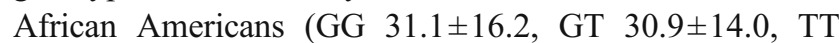
$\left.28.4 \pm 7.0 \mathrm{~kg} / \mathrm{m}^{2} ; p=0.03\right)$.

Family-based studies of TCF7L2 SNPs in Europids Both phenotypic and genotype data for SNPs rs7903146 and rs 12255372 were available in 673 members of 68 families. Although neither SNP showed excess transmission from parents to affected offspring using methods described previously [33-35], logistic regression methods showed a significant association of the TT genotype, for each of the two SNPs, with diabetes penetrance and with increased $60 \mathrm{~min}$ and $90 \mathrm{~min}$ glucose levels, but not with reduced insulin levels or altered HOMA estimates of insulin sensitivity (Table 3; data not shown). Among the subset of 122 non-diabetic family members who underwent frequently sampled IVGTT, neither SNP altered $\mathrm{S}_{\mathrm{I}}, \mathrm{AIR}_{\mathrm{g}}$ or DI (data not shown).

Metabolic studies of TCF7L2 SNPs in unrelated, nondiabetic participants The characteristics of 159 non-diabetic African American and 344 non-diabetic Europid participants are shown in Table 2. The populations were similar for age and BMI, but African Americans had significantly greater insulin secretion $\left(\mathrm{AIR}_{\mathrm{g}}, \mathrm{DI}\right.$, insulinogenic index, $\mathrm{AUC}_{\text {insulin }}$ ) and more favourable blood pressure and lipid profiles than Europids. Given the differences in linkage

Table 3 Measured genotype analysis in families for type 2 diabetes and glucose homeostasis traits

\begin{tabular}{|c|c|c|c|c|c|c|c|c|c|}
\hline \multirow[t]{2}{*}{ Trait } & \multirow[t]{2}{*}{$n$} & \multicolumn{4}{|l|}{ rs7903146 } & \multicolumn{4}{|l|}{ rs 12255372} \\
\hline & & $\mathrm{CC}$ & $\mathrm{CT}$ & TT & $p$ value & GG & GT & $\mathrm{TT}$ & $p$ value \\
\hline $\mathrm{T} 2 \mathrm{DM}$ & 668 & $0.43(0.05)$ & $0.48(0.05)$ & $0.61(0.07)$ & 0.037 & $0.42(0.05)$ & $0.48(0.05)$ & $0.64(0.07)$ & 0.017 \\
\hline $60 \mathrm{~min}$ glucose & 404 & $\begin{array}{l}5.96 \\
(5.78-6.14)\end{array}$ & $\begin{array}{l}6.42 \\
(6.15-6.70)\end{array}$ & $\begin{array}{l}6.66 \\
(6.03-7.36)\end{array}$ & 0.02 & $\begin{array}{l}5.94 \\
(5.78-6.10)\end{array}$ & $\begin{array}{l}6.52 \\
(6.35-6.71)\end{array}$ & $\begin{array}{l}6.45 \\
(5.81-7.18)\end{array}$ & 0.009 \\
\hline 90 min glucose & 187 & $\begin{array}{l}5.34 \\
(5.12-5.53)\end{array}$ & $\begin{array}{l}5.81 \\
(5.55-6.08)\end{array}$ & $\begin{array}{l}6.13 \\
(5.49-6.86)\end{array}$ & 0.034 & $\begin{array}{l}5.32 \\
(5.14-5.51)\end{array}$ & $\begin{array}{l}5.87 \\
(5.67-6.09)\end{array}$ & $\begin{array}{l}6.08 \\
(5.38-6.88)\end{array}$ & 0.022 \\
\hline $60 \mathrm{~min}$ insulin & 374 & $\begin{array}{l}234 \\
(123-447)\end{array}$ & $\begin{array}{l}264 \\
(105-663)\end{array}$ & $\begin{array}{l}275 \\
(218-346)\end{array}$ & 0.152 & $\begin{array}{l}232 \\
(129-419)\end{array}$ & $\begin{array}{l}272 \\
(104-711)\end{array}$ & $\begin{array}{l}263 \\
(206-335)\end{array}$ & 0.065 \\
\hline
\end{tabular}

Means are shown from the measured genotype analysis for traits that were significant or approached significance. Type 2 diabetes (T2DM) is shown as the genotype-specific penetrance (values are mean (SD)). All other traits are shown as mean and $95 \% \mathrm{CIs}$, transformed to the linear scale from the lntransformed results. All means were adjusted to male, age 80 years (type 2 diabetes) or 30 years (homeostasis traits) and BMI $20 \mathrm{~kg} / \mathrm{m}^{2}$. $n$ varied with trait availability and missing genotypes.

Glucose and insulin traits were tested only in non-diabetic individuals. 
disequilibrium, metabolic profiles and association with type 2 diabetes, we analysed Europid and African American populations separately (Table 4, ESM Table 5). Risk alleles for both rs 12255372 and rs7903146 were associated with reduced $\mathrm{S}_{\mathrm{I}}$ in Europids $(p<0.007)$, but not in African Americans. Consistent with reduced $\mathrm{S}_{\mathrm{I}}$ in risk allele carriers, $\mathrm{AUC}_{\text {insulin }}$ was increased. In contrast, no measure of insulin secretion $\left(\mathrm{AIR}_{\mathrm{g}}, \mathrm{DI}, \mathrm{AIR}_{\max }\right.$, insulinogenic index) differed significantly by genotype. $\mathrm{AUC}_{\text {glucose }}$ showed a non-significant trend towards increasing values with heterozygosity and homozygosity for the risk allele (Table 4), but neither $2 \mathrm{~h}$ glucose nor glucose tolerance status (normal vs impaired glucose tolerance) differed by genotype at either marker ( $p>0.7$; data not shown). Among African Americans, $\mathrm{AUC}_{\text {insulin }}$ and the insulinogenic index were reduced in heterozygotes compared with common homozygous individuals, but not in the small number of minor allele homozygotes (Table 4, ESM Table 5). Neither SNP was significantly associated with BMI, waist circumference, WHR or per cent fat in either population (data not shown).

TCF7L2 gene expression We examined adipose tissue in 74 individuals for whom we had both TCF7L2 expression and genotype (13 male, 61 female; 66 Europid, eight African American). Analyses were adjusted for age, sex, ethnicity and BMI using mixed effects regression models. Expression levels did not differ by genotype for either SNP (Table 5 for rs7903146), nor did levels influence $\mathrm{S}_{\mathrm{I}}$ or $\mathrm{AIR}_{\mathrm{g}}$ ( $p>0.2$; data not shown). Glucose tolerance status was not a determinant of gene expression ( $p>0.3$; data not shown). Conclusions were not altered when analyses were restricted to Europid samples. However, in exploratory analyses, significant interaction was found between genotype and BMI to determine expression levels for SNP rs12255732 in all samples $(p=0.003)$ and for rs7903146 in Europid samples $(p=0.03)$.

Muscle tissue was examined from 64 individuals for whom genotypes were available (58 Europid, six African American; eight male, 56 female). Data for rs7903146 are presented in Table 5. A non-significant trend towards lower expression in TT homozygotes was observed for both SNPs $(p>0.25)$; again results did not differ if only Europid samples were included. Muscle TCF7L2 expression was approximately tenfold lower than in adipose. Expression levels did not correlate with and were not significant determinants of $\mathrm{S}_{\mathrm{I}}$ or $\operatorname{AIR}_{\mathrm{g}}\left(r^{2}<0.01, p>0.3\right)$; again, they were not altered by glucose tolerance status ( $p>0.2$; data not shown). Among the

Table 4 Metabolic studies for SNP rs7903146 in unrelated, non-diabetic individuals from Arkansas

\begin{tabular}{|c|c|c|c|c|c|c|c|c|}
\hline \multirow[b]{2}{*}{ Genotype } & \multicolumn{4}{|l|}{ Europid } & \multicolumn{4}{|l|}{ African American } \\
\hline & $\mathrm{CC}$ & $\mathrm{CT}$ & TT & $\begin{array}{l}p \\
\text { value }\end{array}$ & $\mathrm{CC}$ & $\mathrm{CT}$ & TT & $\begin{array}{l}p \\
\text { value }\end{array}$ \\
\hline$n$ & 177 & 136 & 23 & & 84 & 66 & 7 & \\
\hline $\begin{array}{l}\mathrm{S}_{\mathrm{I}}\left(\times 10^{-4} \min ^{-1}\right. \\
{\left[\mu \mathrm{U} / \mathrm{ml}^{-1}\right)^{\mathrm{a}}}\end{array}$ & $\begin{array}{l}3.17 \\
(2.79-3.60)\end{array}$ & $\begin{array}{l}2.94 \\
(2.54-3.40)\end{array}$ & $\begin{array}{l}1.74 \\
(1.24-2.44)\end{array}$ & 0.004 & $\begin{array}{l}2.70 \\
(2.35-3.10)\end{array}$ & $\begin{array}{l}2.91 \\
(2.46-3.43)\end{array}$ & $\begin{array}{l}2.34 \\
(1.45-3.77)\end{array}$ & NS \\
\hline $\mathrm{AIR}_{\mathrm{g}}(\mathrm{pmol} / 1 \times \min )$ & $\begin{array}{l}2183 \\
(1925-2476)\end{array}$ & $\begin{array}{l}2074 \\
(1796-2394)\end{array}$ & $\begin{array}{l}2501 \\
(1793-3488)\end{array}$ & 0.56 & $\begin{array}{l}3456 \\
(2820-4230)\end{array}$ & $\begin{array}{l}3018 \\
(23270-3846)\end{array}$ & $\begin{array}{l}3498 \\
(1740-7026)\end{array}$ & NS \\
\hline $\mathrm{S}_{\mathrm{g}}\left(\min ^{-1}\right)^{\mathrm{b}}$ & $\begin{array}{l}0.0158 \\
(0.0147-0.0169)\end{array}$ & $\begin{array}{l}0.0167 \\
(0.0153-0.0181)\end{array}$ & $\begin{array}{l}0.0141 \\
(0.0116-0.017)\end{array}$ & 0.21 & $\begin{array}{l}0.0175 \\
(0.0155-0.0197)\end{array}$ & $\begin{array}{l}0.0170 \\
(0.0147-0.0195)\end{array}$ & $\begin{array}{l}0.0135 \\
(0.009-0.0203)\end{array}$ & NS \\
\hline $\mathrm{DI}^{\mathrm{c}}$ & $\begin{array}{l}1152 \\
(1001-1326)\end{array}$ & $\begin{array}{l}1061 \\
(903-1248)\end{array}$ & $\begin{array}{l}726 \\
(501-1052)\end{array}$ & 0.067 & $\begin{array}{l}1596 \\
(1278-1993)\end{array}$ & $\begin{array}{l}1450 \\
(1112-1890)\end{array}$ & $\begin{array}{l}1361 \\
(634-2922)\end{array}$ & NS \\
\hline $\begin{array}{l}\text { AUC }_{\text {glucose }} \\
(\mathrm{mmol} / 1 \times \min )\end{array}$ & $\begin{array}{l}834 \\
(809-859)\end{array}$ & $\begin{array}{l}867 \\
(838-898)\end{array}$ & $\begin{array}{l}875 \\
(804-952)\end{array}$ & 0.16 & $\begin{array}{l}794 \\
(758-833)\end{array}$ & $\begin{array}{l}821 \\
(777-869)\end{array}$ & $\begin{array}{l}863 \\
(731-1020)\end{array}$ & NS \\
\hline $\begin{array}{l}\mathrm{AUC}_{\text {insulin }} \\
(\mathrm{pmol} / 1 \times \min )\end{array}$ & $\begin{array}{l}34930 \\
(31687-38504)\end{array}$ & $\begin{array}{l}41361 \\
(36948-46301)\end{array}$ & $\begin{array}{l}48460 \\
(36562-64230)\end{array}$ & 0.016 & $\begin{array}{l}50277 \\
(43594-57983)\end{array}$ & $\begin{array}{l}38899 \\
(33007-45842)\end{array}$ & $\begin{array}{l}45851 \\
(26597-79041)\end{array}$ & $0.06^{\mathrm{d}}$ \\
\hline $\begin{array}{l}\text { Insulinogenic index } \\
(\mathrm{pmol} / \mathrm{mmol})\end{array}$ & $\begin{array}{l}91.5 \\
(81.9-102.1)\end{array}$ & $\begin{array}{l}97.8 \\
(86.1-111.1)\end{array}$ & $\begin{array}{l}102.0 \\
(74.3-140.0)\end{array}$ & 0.64 & $\begin{array}{l}170 \\
(137-212)\end{array}$ & $\begin{array}{l}110 \\
(85-141)\end{array}$ & $\begin{array}{l}127 \\
(55-291)\end{array}$ & $0.033^{\mathrm{e}}$ \\
\hline $\mathrm{AIR}_{\max }(\mathrm{pmol})^{\mathrm{f}}$ & $\begin{array}{l}1184 \\
(1035-1354)\end{array}$ & $\begin{array}{l}1356 \\
(1162-1582)\end{array}$ & $\begin{array}{l}1753 \\
(1232-2495)\end{array}$ & 0.078 & $\begin{array}{l}1123 \\
(910-1385)\end{array}$ & $\begin{array}{l}1111 \\
(874-1412)\end{array}$ & $\begin{array}{l}874 \\
(465-1644)\end{array}$ & NS \\
\hline
\end{tabular}

$p$ values are shown for the general model.

${ }^{\mathrm{a}}$ Units are taken from the MINMOD program. To convert values to SI units $\left(\times 10^{-4} \mathrm{~min}^{-1}[\mathrm{pmol} / 1]^{-1}\right)$ multiply by 0.167 .

${ }^{\mathrm{b}} \mathrm{S}_{\mathrm{g}}$ (glucose effectiveness) is a measure of the ability of glucose to promote its own uptake.

${ }^{\mathrm{c}} \mathrm{DI}$ is calculated as $\mathrm{S}_{\mathrm{I}} \times \mathrm{AIR}_{\mathrm{g}}$ for individual values.

${ }^{\mathrm{d}} \mathrm{C} / \mathrm{C}$ vs $\mathrm{C} / \mathrm{T}, p=0.018$

${ }^{\mathrm{e}} \mathrm{C} / \mathrm{C}$ vs $\mathrm{C} / \mathrm{T}, p=0.009$

${ }^{\mathrm{f}}$ Number of participants for $\mathrm{AIR}_{\max }$ was reduced to 78/56/10 for CC/CT/TT genotypes at rs 7903146 in Europids, to 28/29/3 in African Americans and to $75 / 63 / 6$ for glucose tolerance test-related traits in African Americans, respectively. 
Table 5 Gene expression levels in subcutaneous adipocytes and muscle from non-diabetic individuals by rs7903146 genotype

\begin{tabular}{llll}
\hline Tissue & CC & CT & TT \\
\hline $\begin{array}{l}\text { Adipose } \\
n\end{array}$ & 39 & 28 & 7 \\
$\quad$ Ratio & $0.948(0.831-1.082)$ & $0.980(0.840-1.14)$ & $0.921(0.706-1.200)$ \\
Muscle & 30 & 30 & 4 \\
$n$ & $0.371(0.284-0.486)$ & $0.338(0.246-0.464)$ & $0.262(0.136-0.501)$ \\
Ratio & & & \\
\hline
\end{tabular}

Numbers of participants for each tissue and with each genotype are shown.

Ratios of TCF7L2 to 18S RNA are given as the mean and 95\%CIs, obtained from marginal means in a mixed effect model adjusting for age and ln(BMI) For data for rs 12255372 , see ESM Table 5.

No differences approach significance: $p>0.4$

38 individuals for whom both fat and muscle tissue were available, expression levels showed no significant correlation between tissues $\left(r^{2}=0.015, p=0.6\right)$.

We next examined transformed lymphocyte cDNA from transformed lymphocytes from 25 Europid (10 non-diabetic, 15 diabetic) and 30 African American (10 non-diabetic, 20 diabetic) participants. African Americans had lower expression levels $(0.94 \pm 0.58)$ than Europids $(1.39 \pm 1.38 ; p=0.03)$, a difference not observed in the smaller number of adipose and muscle samples available from African American participants. Regardless of whether African American and Europid samples were considered separately or together, expression levels did not differ by diabetic status or by genotype (Table 6). In an exploratory analysis, rs7903146 interacted with diabetic status to reduce TCF $7 L 2$ expression in non-diabetic TT homozygotes relative to common CC homozygotes, whereas levels were increased in CT and TT diabetic participants (Fig. 1).

\section{Discussion}

TCF7L2 is the best replicated and strongest genetic risk factor identified to date for type 2 diabetes in Europids, with SNP rs7903146 showing the most consistent and

Table 6 TCF7L2 expression studies of transformed lymphocytes in diabetic and non-diabetic participants of Europid and African American ancestry

\begin{tabular}{|c|c|c|c|c|}
\hline \multirow[b]{2}{*}{ Trait } & \multicolumn{4}{|l|}{ Level } \\
\hline & $\mathrm{CC}(7 \mathrm{E} / 13 \mathrm{AA})$ & CT (8 E/13 AA) & TT (9 E/4 AA) & $p$ value \\
\hline \multicolumn{5}{|l|}{ Rs7903146 genotype } \\
\hline All & $0.89(0.69-1.16)$ & $0.92(0.70-1.21)$ & $0.70(0.48-1.02)$ & 0.48 \\
\hline Europid & $1.03(0.66-1.60)$ & $1.07(0.44-2.62)$ & $1.02(0.37-2.85)$ & 0.97 \\
\hline African American & $0.74(0.18-3.04)$ & $0.85(0.23-3.14)$ & $0.69(0.27-1.77)$ & 0.82 \\
\hline \multicolumn{5}{|l|}{ Diabetes } \\
\hline \multicolumn{5}{|l|}{ Control (10 E/10 AA) } \\
\hline Europid & $0.87(0.43-1.76)$ & & - & 0.063 \\
\hline African American & $0.89(0.29-2.73)$ & & - & 0.42 \\
\hline \multicolumn{5}{|l|}{ Type 2 diabetes (15 E/20 AA) } \\
\hline Europid & & $1.34(0.39-4.56)$ & & 0.063 \\
\hline African American & & $0.72(0.20-2.85)$ & & 0.42 \\
\hline \multicolumn{5}{|l|}{ Ethnicity } \\
\hline \multicolumn{5}{|l|}{ Control (10 E/10 AA) } \\
\hline Europid $(n=24)$ & $1.02(0.80-1.30)$ & & & 0.03 \\
\hline \multicolumn{5}{|l|}{$\mathrm{T} 2 \mathrm{DM}(15 \mathrm{~W} / 20 \mathrm{AA})$} \\
\hline African American $(n=30)$ & & $0.68(0.52-0.89)$ & & \\
\hline
\end{tabular}

Comparison of ratios of TCF7L2 to 18S RNA for Epstein-Barr virus transformed lymphocytes from Europid and African American participants across genotype and diabetes status.

All ratios were ln-transformed and are presented as geometric means with 95\%CIs.

Numbers of participants are shown in parentheses for each category.

$p$ values were calculated by analysis of variance.

For the presentation of marginal means from a mixed effects regression mode, see Fig. 1.

$A A$ : African American, E: Europid 


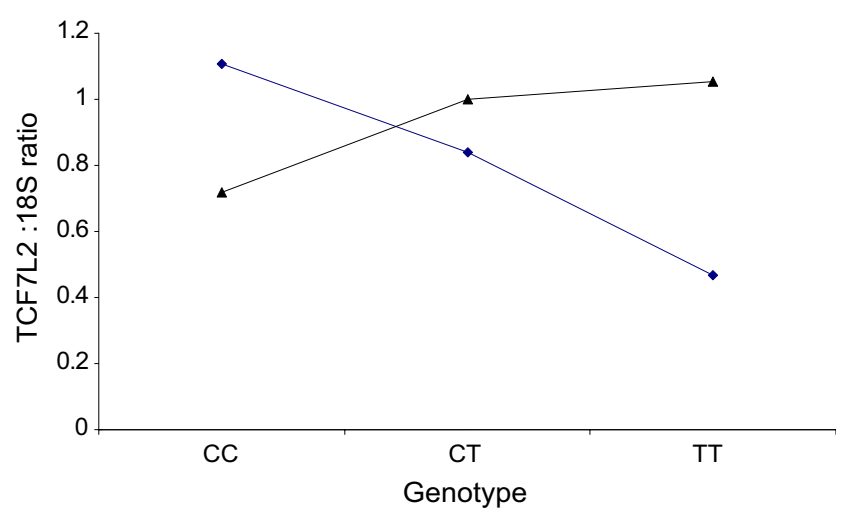

Fig. 1 Expression was evaluated in a mixed effects model with ethnicity and diagnosis (diabetic or non-diabetic) as co-factors. Expression ratio is for the $5^{\prime}$ primer set normalised to $18 \mathrm{~S}$ RNA. Number of samples: $C C$ (7 control, 13 diabetic); $C T$ (8 control, 13 diabetic); TT (9 control, 4 diabetic). diamonds, control; triangles, diabetic

strongest association [6]. No coding variant explains the TCF7L2 association with type 2 diabetes [4]. Our study replicates this association in Europids, in both a casecontrol study and in family-based analyses, with an OR for rs 7903146 of 1.7 , which is comparable with many previous studies [8]. Furthermore, we found significantly higher post-challenge plasma glucose levels in non-diabetic carriers of the TCF $7 L 2$ risk alleles, both in members of highrisk families and in unrelated individuals. In contrast, we found no association in a similarly ascertained African American cohort. Few studies of TCF7L2 in African Americans have been published. In the relatively small African American subset of the Diabetes Prevention Program [11] and in 385 Afro-Caribbean participants from the UK [13], TCF7L2 was not associated with type 2 diabetes mellitus. Because the minor (T) allele frequency at rs7903146 is even higher in African Americans than in Europids, allele frequency cannot explain this discrepancy. In contrast, Helgason et al. [14] did replicate the association of rs7903146 in families from West Africa (RR 1.45, $p=$ 0.002 after correcting for relatedness and ancestry). Differences in linkage disequilibrium between populations of African and European ancestry are unlikely to explain this discrepancy, given that rs7903146 appears to be the causative SNP [14]. Using our African American sample size, an OR of 1.5 (close to the 1.45 estimated in West Africans) and the control minor allele frequency of 0.30 , we had $85 \%$ power to detect an association at $p<0.05$. Were the OR only 1.3 , our power would fall to $52 \%$. Alternatively, gene-gene or gene-environment interactions could easily explain the differences among populations [36], particularly given the different lifestyles of West African and Arkansas African American individuals.

$T C F 7 L 2$ binds to the promoter of the proglucagon gene in gut endocrine L cells [15], thus potentially acting through glucagon-like peptide 1 to affect insulin secretion. Indeed, some but not all studies have shown impaired insulin secretion to oral glucose in individuals with the rs7903126 TT genotype $[6,11,18]$. In contrast, we did not find evidence for such an effect. Although we found nominal evidence for reduced insulin secretion in African American carriers of the risk alleles, insulin secretion was higher among Europid individuals with risk alleles, consistent with reduced insulin sensitivity. Whereas we did observe the trend towards lower DI reported in smaller studies of Damcott et al. [10] and Munoz et al. [17]), this trend was driven by reduced $\mathrm{S}_{\mathrm{I}}$. However, post-challenge plasma glucose was increased with the risk allele among non-diabetic members of high-risk families (Table 3), with a similar trend among non-diabetic, unrelated individuals (Table 4). Nonetheless, neither $2 \mathrm{~h}$ glucose as a quantitative trait nor glucose tolerance $(2 \mathrm{~h}$ glucose higher than $7.8 \mathrm{mmol} / \mathrm{l}$ ) as a dichotomous trait was associated with $T C F 7 L 2$ genotype $(p>0.7)$.

$T C F 7 L 2$, which is widely expressed, acts downstream of WNT to complex with $\beta$-catenin, which in turn activates transcription of a wide variety of genes, including those implicated in cell proliferation and neoplasia [37, 38]. The WNT pathway also plays a role in adipogenesis [39]; hence $T C F 7 L 2$, which is well expressed in adipose, may play a role in insulin action and insulin sensitivity. Damcott et al. [10] first reported reduced $\mathrm{S}_{\mathrm{I}}$ in non-diabetic Europid participants with TCF7L2 risk alleles. Our data confirm that association in a much larger Europid population, with a $45 \%$ reduction in $\mathrm{S}_{\mathrm{I}}$ among TT homozygotes. In contrast, Munoz et al. found no association with $\mathrm{S}_{\mathrm{I}}$ in 138 Europid women [17]; we found no association in 122 non-diabetic members of Utah families (the current study); and Scott et al. [7] found no association with $S_{I}$ in members of Finnish families. Munoz et al. found a non-significant trend towards reduced $\mathrm{S}_{\mathrm{I}}$ and reduced $\mathrm{AIR}_{\mathrm{g}}$ among 118 African American women, which was not observed in our study. Differences in ascertainment, relatively small samples for published studies, particularly when considering the rare allele homozygote frequency, and possible gene-gene or gene-environment interactions may explain these differences. Neither the previously published studies nor we attempted to correct for multiple testing (two SNPs, several metabolic traits, with both the SNPs and traits showing correlation). Hence, some of the nominal $p$ values $(0.01<p<0.05)$ in our studies and published reports may be spurious.

Non-coding variants of TCF7L2 may influence glucose homeostasis by changing transcription (regulation) or splicing and may do so in a tissue-specific fashion. To our knowledge, this is the first study to examine the role of ethnicity and genotype in TCF7L2 gene expression or the role of muscle and adipocyte $T C F 7 L 2$ expression in insulin sensitivity. We found no genotypic effects on TCF7L2 expression levels in adipose or muscle, nor any correlation 
of TCF7L2 mRNA levels with $\mathrm{S}_{\mathrm{I}}$ or BMI. In contrast, we did find a trend towards genotype determination of gene expression in transformed lymphocytes, where expression was decreased in African American and Europid nondiabetic individuals, but increased in diabetic individuals with the TT risk genotype. As this study was small (24 nondiabetic individuals, 30 diabetic individuals) and included two ethnic groups that themselves show differences in expression, this unexpected finding requires further study. Because individuals for whom transformed lymphocytes were available were not the individuals who had undergone adipose and muscle biopsies, we were unable to examine the correlation in gene expression between these tissues. Given the multiple splice forms of TCF7L2, the lack of genotype effect on total TCF7L2 expression measured in this study and the lack of correlation of adipocyte or muscle TCF7L2 expression with $\mathrm{S}_{\mathrm{I}}$, we believe that tissue-specific splicing deserves further study.

Acknowledgements This work was supported by grants from National Institutes of Health/National Institute of Diabetes, Digestive and Kidney Disease (NIH/NIDDK) DK39311 (S. C. Elbein), DK71277 (P. A. Kern) and by the Research Service of the Department of Veterans Affairs (Merit funds to S. C. Elbein, P. A. Kern and N. Rasouli; REAP funds). Participants ascertainment was supported in part by grants from the American Diabetes Association (S. C. Elbein), NIH/NIDDK DK59311 (S. C. Elbein) and by the General Clinical Research Center, grant M01RR14288 from National Center for Research Resources (National Institutes of Health), to the University of Arkansas for Medical Sciences.

Duality of interest The authors declare that there is no duality of interest associated with this study.

\section{References}

1. Altshuler D, Hirschhorn JN, Klannemark M et al (2000) The common PPARgamma Pro12Ala polymorphism is associated with decreased risk of type 2 diabetes. Nat Genet 26:76-80

2. Florez JC, Burtt N, de Bakker PI et al (2004) Haplotype structure and genotype-phenotype correlations of the sulfonylurea receptor and the islet ATP-sensitive potassium channel gene region. Diabetes 53:1360-1368

3. Gloyn AL, Weedon MN, Owen KR et al (2003) Large-scale association studies of variants in genes encoding the pancreatic beta-cell KATP channel subunits Kir6.2 (KCNJ11) and SUR1 (ABCC8) confirm that the KCNJ11 E23K variant is associated with type 2 diabetes. Diabetes 52:568-572

4. Grant SF, Thorleifsson G, Reynisdottir I et al (2006) Variant of transcription factor 7-like 2 (TCF7L2) gene confers risk of type 2 diabetes. Nat Genet 38:320-323

5. Groves CJ, Zeggini E, Minton J et al (2006) Association analysis of 6,736 U.K. subjects provides replication and confirms TCF7L2 as a type 2 diabetes susceptibility gene with a substantial effect on individual risk. Diabetes 55:2640-2644

6. Saxena R, Gianniny L, Burtt NP et al (2006) Common single nucleotide polymorphisms in TCF7L2 are reproducibly associated with type 2 diabetes and reduce the insulin response to glucose in nondiabetic individuals. Diabetes 55:2890-2895

7. Scott LJ, Bonnycastle LL, Willer CJ et al (2006) Association of transcription factor 7-like 2 (TCF7L2) variants with type 2 diabetes in a Finnish sample. Diabetes 55:2649-2653

8. Cauchi S, Meyre D, Dina C et al (2006) Transcription factor TCF7L2 genetic study in the French population: expression in human b-cells and adipose tissue and strong association with type 2 diabetes. Diabetes 55:2903-2908

9. Vliet-Ostaptchouk JV, Shiri-Sverdlov R, Zhernakova A et al (2007) Association of variants of transcription factor 7-like 2 (TCF7L2) with susceptibility to type 2 diabetes in the Dutch Breda cohort. Diabetologia 50:59-62

10. Damcott CM, Pollin TI, Reinhart LJ et al (2006) Polymorphisms in the transcription factor 7-like 2 (TCF7L2) gene are associated with type 2 diabetes in the Amish: replication and evidence for a role in both insulin secretion and insulin resistance. Diabetes 55:2654-2659

11. Florez JC, Jablonski KA, Bayley N et al (2006) TCF7L2 polymorphisms and progression to diabetes in the Diabetes Prevention Program. N Engl J Med 355:241-250

12. Zhang C, Qi L, Hunter DJ et al (2006) Variant of transcription factor 7-like 2 (TCF7L2) gene and the risk of type 2 diabetes in large cohorts of U.S. women and men. Diabetes 55:2645-2648

13. Humphries SE, Gable D, Cooper JA et al (2006) Common variants in the TCF7L2 gene and predisposition to type 2 diabetes in UK European Europids, Indian Asians and Afro-Caribbean men and women. J Mol Med 84:1-10

14. Helgason A, Palsson S, Thorleifsson G et al (2007) Refining the impact of TCF7L2 gene variants on type 2 diabetes and adaptive evolution. Nat Genet 39:218-225

15. Yi F, Brubaker PL, Jin T (2005) TCF-4 mediates cell type-specific regulation of proglucagon gene expression by beta-catenin and glycogen synthase kinase-3beta. J Biol Chem 280:1457-1464

16. Kennell JA, MacDougald OA (2005) Wnt signaling inhibits adipogenesis through beta-catenin-dependent and -independent mechanisms. J Biol Chem 280:24004-24010

17. Munoz J, Lok KH, Gower BA et al (2006) Polymorphism in the transcription factor 7-like 2 (TCF7L2) gene is associated with reduced insulin secretion in nondiabetic women. Diabetes 55:3630-3634

18. Cauchi S, Meyre D, Choquet H et al (2006) TCF7L2 variation predicts hyperglycemia incidence in a French general population: the data from an epidemiological study on the Insulin Resistance Syndrome (DESIR) study. Diabetes 55:3189-3192

19. Elbein SC, Hasstedt SJ, Wegner K, Kahn SE (1999) Heritability of pancreatic beta-cell function among nondiabetic members of Caucasian familial type 2 diabetic kindreds. J Clin Endocrinol Metab 84:1398-1403

20. Raffel LJ, Robbins DC, Norris JM et al (1996) The GENNID study. A resource for mapping the genes that cause NIDDM. Diabetes Care 19:864-872

21. Wang H, Zhang $\mathrm{H}$, Jia $\mathrm{Y}$ et al (2004) Adiponectin receptor 1 gene (ADIPOR1) as a candidate for type 2 diabetes and insulin resistance. Diabetes 53:2132-2136

22. Wang H, Zhang Z, Chu W, Hale T, Cooper JJ, Elbein SC (2005) Molecular screening and association analyses of the interleukin 6 receptor gene variants with type 2 diabetes, diabetic nephropathy, and insulin sensitivity. J Clin Endocrinol Metab 90:1123-1129

23. Rasouli N, Raue U, Miles LM et al (2005) Pioglitazone improves insulin sensitivity through reduction in muscle lipid and redistribution of lipid into adipose tissue. Am J Physiol Endocrinol Metab 288:E930-E934

24. Rasouli N, Hale T, Kahn SE, Spencer HJ, Elbein SC (2005) Effects of short term experimental insulin resistance and family history of diabetes on pancreatic b-cell function in nondiabetic individuals. J Clin Endocrinol Metab 90:5825-5833 
25. Elbein SC, Hoffman MD, Teng K, Leppert MF, Hasstedt SJ (1999) A genome-wide search for type 2 diabetes susceptibility genes in Utah Caucasians. Diabetes 48:1175-1182

26. Das SK, Hasstedt SJ, Zhang Z, Elbein SC (2004) Linkage and association mapping of a chromosome 1q21-q24 type 2 diabetes susceptibility locus in Northern European Caucasians. Diabetes 53:492-499

27. Kern PA, Di Gregorio GB, Lu T, Rassouli N, Ranganathan G (2003) Adiponectin expression from human adipose tissue: relation to obesity, insulin resistance, and tumor necrosis factoralpha expression. Diabetes 52:1779-1785

28. Duval A, Rolland S, Tubacher E, Bui H, Thomas G, Hamelin R (2000) The human T-cell transcription factor-4 gene: structure, extensive characterization of alternative splicings, and mutational analysis in colorectal cancer cell lines. Cancer Res 60:3872-3879

29. Barrett JC, Fry B, Maller J, Daly MJ (2005) Haploview: analysis and visualization of LD and haplotype maps. Bioinformatics 21:263-265

30. Pacini G, Bergman RN (1986) MINMOD: a computer program to calculate insulin sensitivity and pancreatic responsivity from the frequently sampled intravenous glucose tolerance test. Comput Methods Programs Biomed 23:113-122

31. Boston RC, Stefanovski D, Moate PJ, Sumner AE, Watanabe RM, Bergman RN (2003) MINMOD Millennium: a computer program to calculate glucose effectiveness and insulin sensitivity from the frequently sampled intravenous glucose tolerance test. Diabetes Technol Ther 5:1003-1015

32. Saad MF, Steil GM, Kades WW et al (1997) Differences between the tolbutamide-boosted and the insulin-modified minimal model protocols. Diabetes 46:1167-1171

33. Hasstedt SJ (2006) jPAP: document-driven software for genetic analysis. Genet Epidemiol 29:255

34. Wang H, Chu W, Das SK, Ren Q, Hasstedt SJ, Elbein SC (2002) Liver pyruvate kinase polymorphisms are associated with type 2 diabetes in northern European Caucasians. Diabetes 51:2861-2865

35. Hasstedt SJ (2001) PAP: pedigree analysis package, V5. Department of Human Genetics, University of Utah, Salt Lake City, UT, USA

36. Lin PI, Vance JM, Pericak-Vance MA, Martin ER (2007) No gene is an island: the flip-flop phenomenon. Am J Hum Genet 80: $531-538$

37. de Lau W, Barker N, Clevers H (2007) WNT signaling in the normal intestine and colorectal cancer. Front Biosci 12:471-491

38. Mulholland DJ, Read JT, Rennie PS, Cox ME, Nelson CC (2003) Functional localization and competition between the androgen receptor and T-cell factor for nuclear beta-catenin: a means for inhibition of the Tcf signaling axis. Oncogene 22:5602-5613

39. Ross SE, Hemati N, Longo KA et al (2000) Inhibition of adipogenesis by Wnt signaling. Science 289:950-953 